\title{
Object recognition through eavesdropping: Passive echolocation in bottlenose dolphins
}

\author{
MARK J. XITCO, JR. \\ The Living Seas, Epcot, Lake Buena Vista, Florida \\ and Southern Methodist University, Dallas, Texas \\ and \\ HERBERT L. ROITBLAT \\ University of Hawai, Honolulu, Hawaii
}

\begin{abstract}
A bottlenose dolphin (Tursiops truncatus) demonstrated the ability to select the matching object in a matching-to-sample task after listening to another dolphin inspect the sample object via echolocation. The listener was prevented from inspecting the sample himself. In Experiment 1, with objects familiar to both dolphins, the listener's performance was significantly better than chance. In Experiment 2, objects familiar to only one of the dolphins were used. On these trials, the listener's performance was significantly better than chance only when the inspecting dolphin made a correct choice. Analysis of the listener's responses when the inspector made an error demonstrated that this contingency was not due to the listener's matching the inspector's response, but was apparently due instead to inadequate information in the echo. The results suggest that the listener was able to "eavesdrop" on echoes produced by the inspector's clicks and derive characteristics of the sample object.
\end{abstract}

The formidable sensory capabilities of the dolphin's echolocation system are well documented ( $\mathrm{Au}, 1993$; Moore, 1988). However, discussion of the role of echolocation in the context of dolphin social or communicatory behavior has been, for the most part, speculative. Caldwell and Caldwell (1977) suggested that dolphins could detect the presence of conspecifics and associated concentrations of prey by listening for the outgoing echolocation signals, or clicks, produced by other dolphins as they foraged. This phenomenon has since been documented in bats (Barclay, 1982; Fenton, 1980; Leonard \& Fenton, 1984), which also echolocate. Scronce and C. S. Johnson (1976) demonstrated experimentally that a listening dolphin could detect the presence of a target object ensonified by an artificial projector. The dolphin was prevented from using his own echolocation clicks by an acoustic mask which covered his upper jaw and melon. Targets were ensonified by using a synthetic signal designed to resemble the dolphin's click. The animal was able to detect the target object presumably by listening for the resulting echoes.

Herman and Tavolga (1980) suggested that a dolphin might be able to determine more than just the presence of

This research was funded through contracts to M.J.X. from Walt Disney Imagineering, Research and Development. It was made possible by the dedication of the staff of The Living Seas, Epcot, and the 30 undergraduate interns who participated on the project. Thanks to John Gory for the advice and assistance he provided throughout the study, and to John Gory and Don Kent for their comments on the manuscript. Correspondence should be addressed to M. J. Xitco, Jr., NRaD, Code 351, 53420 Craig Rd., San Diego, CA 92152-6267 (e-mail: xitco@nosc.mil). a target by listening. They speculated that target features, such as relative distance or novelty, might be identified by characteristic changes in the interclick interval. Penner (1988) found that the interval between clicks depended strongly on the distance between the dolphin and the target being inspected. He argued that echolocation clicks generated by one dolphin might thereby direct another dolphin's attention to a particular location or distance. In addition, it has been suggested that information characterizing object features might be carried by the structure of outgoing clicks, but such social transmission seems very unlikely. Although dolphins adjust the peak frequency and intensity of echolocation clicks in response to environmental noise (Au, Carder, Penner, \& Scronce, 1985; Moore \& Pawloski, 1990; Romanenko, 1990), frequency and amplitude are correlated, and the range of variables that can be varied independently appears quite limited (Au, Schusterman, \& Kersting 1980; Bel'kovich \& Dubrovskiy, 1976; Roitblat, Penner, \& Nachtigall, 1990a; Thompson \& Herman, 1975). The form of echolocation clicks emitted by a dolphin tend to be very stereotypical, regardless of the object.

Other speculation on the role of echolocation in dolphin social and communicatory behavior has focused on the information contained within returning echoes. Both Jerison (1986) and Dawson (1991) have proposed that it might be possible for dolphins to "eavesdrop" on the echoes generated as others inspected targets, and that an ability to interpret echoes produced by the echoic inspections of others might underlie a system of complex communication consistent with the dolphin's large brain (Morgane, Jacobs, \& Galaburda, 1986) and sophisticated social behavior (C. M. Johnson \& Norris, 1986). The struc- 
ture of echoes, unlike that of outgoing clicks, has been shown to vary systematically with certain target characteristics. Object features such as shape (Nachtigall, 1980) and material and internal structure (Au \& Hammer, 1980 ) have been found to produce distinctive highlights, energy peaks of particular frequency occurring at a particular time, within echoes. The manipulation of these highlights, within artificially produced echoes from "phantom" sample objects, has been shown to affect the choice made by dolphins in a matching task (see $\mathrm{Au}$, Moore, \& Martin, 1987, for a review). In addition, the analysis of within-echo frequency structure has been central to neural network models of the echolocating dolphin's decision-making process (Roitblat, Moore, Nachtigall, \& Penner,1991), as well as in discussions of the role of energy spectrum analysis (R. A. Johnson, 1980) and time-separation pitch (Moore, Hall, Friedl, \& Nachtigall, 1984) in identifying target features.

These speculations are limited, however, by the observation that the frequency pattern of outgoing echolocation clicks is strongly dependent on the angle between the dolphin's rostrum and the target ( $\mathrm{Au}, 1993)$. For example, $\mathrm{Au}$ (1993) reported that the peak frequency of an echolocation click measured on axis (i.e., directly in front of the dolphin) was $122 \mathrm{kHz}$. The same click measured $10^{\circ}$ to the right of the axis had an amplitude that was $10 \mathrm{~dB}$ lower and a peak frequency of only $38 \mathrm{kHz}$. In addition, the spectral structure of the echo is also strongly dependent on the three-dimensional structure of the face of the object from which the echo is reflected (see, e.g., Helweg, Roitblat, Nachtigall, \& Hautus, 1996). Therefore, the dolphin's ability to recognize detailed echo information resulting from another dolphin's clicks is likely to depend strongly on the angle between the two dolphins.

In the present study, we examined the ability of one dolphin to select an object after listening to another dolphin inspect that object with echolocation. In Experiment 1 , objects familiar to both dolphins were used. In Experiment 2, the objects were familiar to only one of the dolphins at a time, so that the other dolphin's performance could not be attributed to some learned pattern of behavior associated with the specific target or to some artifact associated with the specific targets used in Experiment 1 . A demonstration of the dolphin's ability to acquire information about target features through passive listening may suggest a wider role for echolocation within the dolphin's social and communication systems. Such success of the listening dolphin would be due, presumably, to its listening in on echoes generated during the other dolphin's active examination of the target.

A demonstration of "passive echolocation object recognition" would also provide data relevant to an understanding of the underlying neurophysiological mechanisms of dolphin echolocation. Little is known about the neural mechanisms underlying dolphin echolocation, but studies of bats suggest that neural events derived from the outgoing echolocation signal play a critical role in the processing of echo highlights (Suga, 1990). The neural system for processing bat signals appears to consist of a bank of frequency-tuned neural "delay lines," each of which is activated by the outgoing chirp. Each line synapses with frequency-tuned lines carrying information about the returning echo after a specific delay. Hence, the coincidence of the delayed representation of the frequency structure of the outgoing chirp and the frequency structure of the returning echo gives a good indication of the distance to the echolocated object and its speed (via Doppler). The bat is thought to derive a temporal or range "image" of the surfaces reflecting the echo. In this system, the production of an outgoing chirp is essential to processing the echo (in order to activate the delay lines), so the bat would be predicted not to be able to derive information about target attributes if it did not produce the outgoing signal. If dolphins use similar mechanisms, dolphins too should not be able to process returns from another dolphin's outgoing click.

\section{EXPERIMENT 1}

\section{Method}

Subjects. The subjects, Bob and Toby, were 2 adolescent male Atlantic bottlenose dolphins (Tursiops truncatus) housed at the Living Seas, Epcot. At the beginning of the study, both dolphins were approximately 7 years old and had been participating in a daily training program for 4 years. Prior to the present study, the dolphins had only limited exposure to experimental training. During research sessions, the dolphins typically consumed one quarter of their daily ration of approximately $9.5 \mathrm{~kg}$ of food, composed of a mixture of herring (Culpia harengus), mackerel (Scomber japonicus), and capelin (Mallotus villosus)

General Procedure and Apparatus. The dolphins were trained to perform a three-alternative, identity matching-to-sample task. Matching-to-sample techniques have been used with dolphins to study their perception of, and memory for, auditory stimuli (Herman \& Gordon, 1974), three-dimensional (Herman, Hovancik, Gory, \& Bradshaw, 1989) and two-dimensional (Hunter, 1988) visual stimuli, and echoic stimuli (Roitblat, Penner, \& Nachtigall, 1990b). We began each trial by presenting the subject with a sample stimulus. The sample was then removed, and the subject was required to select an identical stimulus from among a set of alternatives that included two alternative distractor stimuli.

The stimuli in Experiment 1 were 18 three-dimensional objects that varied in size, shape, and material. They are described in Figure 1. The objects had one of four shapes (cube, cylinder, grill, or plate) and were made of one of three materials (aluminum, ceramic, or wood). Grills and plates were solid, whereas cylinders and cubes were either solid or hollow. The hollow cylinders and cubes were filled with water. The results of numerous echolocation studies (Au \& Hammer, 1980; Au et al., 1980; Bagdonis, Bel'kovich, \& Krushinskaya, 1970; Evans \& Powell, 1967; Hammer \& Au, 1980; Nachtigall, 1980; Nachtigall, Murchison, \& Au, 1980 ) suggested that these objects would be readily discriminated by the dolphins.

The positions of the experimenters, dolphins, and apparatus are shown in Figure 2. Training and testing were conducted in the main aquarium at The Living Seas, Epcot, with both dolphins present. The aquarium is circular in shape, $61 \mathrm{~m}$ in diameter and $8 \mathrm{~m}$ deep, with a volume of 22 million liters. It is designed to resemble a Caribbean reef environment and contains numerous structures, including artificial reefs and a central underwater viewing area for guests at the exhibit. The aquarium is also inhabited by approximately 3,000 other animals, including sharks, rays, sea turtles, and various species of reef fish. 


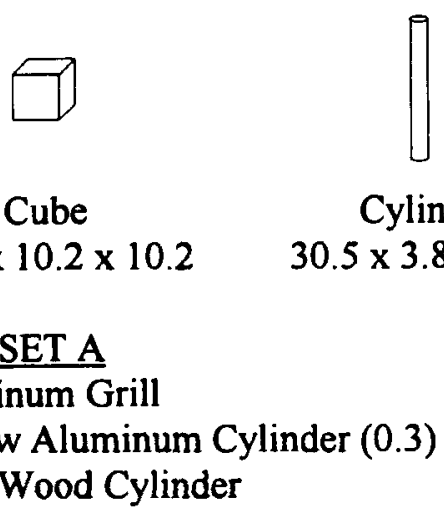

SET B

Ceramic Grill

Hollow Ceramic Cube (0.6)

Wood Grill

\author{
SET C \\ Solid Ceramic Cylinder \\ Hollow Wood Cube (0.6) \\ Solid Wood Cube
}

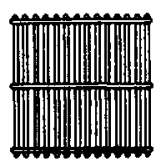

Grill

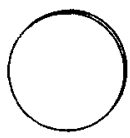

Plate
$30.5 \times 30.5 \times 0.6 \quad 26 \times 26 \times 0.6$

\author{
SET D \\ Solid Aluminum Cylinder \\ Solid Aluminum Cube \\ Hollow Ceramic Cylinder (0.3)
}

\author{
SET E \\ Aluminum Plate \\ Hollow Wood Cylinder (0.3) \\ Wood Plate
}

\begin{abstract}
Figure 1. Stimulus objects used in Experiment 1. Objects had one of four shapes and were made out of one of three materials. The dimensions, in centimeters, listed for each object are height $\times$ width $\times$ depth. Wall thickness, in centimeters, for each hollow object is shown in parentheses. The objects are shown in the orientation in which they were presented to the dolphins as the sample. During training, objects were assigned to sets such that two of the objects in each set were the same shape, two were made from the same material, and two were solid and one was hollow. The sets were presented to the dolphins in counterbalanced fashion in order to control for order effects.
\end{abstract}

\begin{abstract}
Stimulus objects were presented underwater behind visual screens made from $0.10-\mathrm{mm}$-thick, black polyethylene sheeting, pulled taut over frames of PVC plastic pipe. Although the screens were visually opaque, their acoustic properties allowed the dolphins to inspect the objects by using echolocation. On each trial, the sample object was presented approximately $30 \mathrm{~cm}$ below the water's surface behind a centrally located screen used by both dolphins. This sample screen was $1.22 \mathrm{~m}$ wide and $1.52 \mathrm{~m}$ high. It was secured $30 \mathrm{~cm}$ in front of a floating platform in such a way that the screen extended approximately $\mathrm{l} \mathrm{m}$ below the water's surface. Two acoustic boxes were secured between the floating platform and the sample screen. The acoustic boxes measured $46 \mathrm{~cm}$ high, $46 \mathrm{~cm}$ wide, and $10 \mathrm{~cm}$ deep and were open on the top and on one side. Their walls were made of $0.63-\mathrm{cm}$-thick, closed-cell neoprene rubber, similar to the material used by Brill, Sevenich, Sullivan, Sustman, and Witt (1988) to attenuate dolphin echolocation signals. The boxes were submerged to a depth of approximately $30 \mathrm{~cm}$ and positioned to either side of the center of the sample screen, separated by a distance of $46 \mathrm{~cm}$. The sample object was presented behind the center of the sample screen, between the acoustic boxes. A trainer working from the floating platform held the sample in position by hand in a fixed orientation. The alternative objects were presented behind visual screens (choice stations) positioned approximately $10 \mathrm{~m}$ to either side of the sample screen and $4 \mathrm{~m}$ below the surface. Alternative objects were placed by divers, each of whom was ignorant of the identity of the sample. One dolphin made selections from the screen on the left; the other made selections from the screen on the right. These screens were $3.35 \mathrm{~m}$ long and $0.91 \mathrm{~m}$ high. Alternative objects were placed behind the screens in such a way that adjacent objects
\end{abstract}

were separated by a distance of $1.22 \mathrm{~m}$. Each alternative object was held in place $20 \mathrm{~cm}$ behind the screen by an elastic band. During the trial, the alternative objects were allowed to rotate freely around their vertical axis. A large acoustic box was attached to the bottom of each screen. These large boxes measured $1.52 \mathrm{~m}$ long, $61 \mathrm{~cm} \mathrm{high,} \mathrm{and} 30 \mathrm{~cm}$ deep and were open on the back side. Objects not in use on a particular trial were stored inside these boxes to prevent the dolphin from echolocating on them. Note that each dolphin's choice station was separated from the other by a substantial distance. A dolphin facing his own choice station had his back nearly to the other dolphin and hence could not actively echolocate on the other dolphin and his choice. Furthermore, the order of the objects in the choice station (i.e., in the left, middle, or right choice position) was determined independently for the 2 dolphins, so 1 dolphin could not use the visible position of the other dolphin during its choice as a cue.

At the start of an "active" trial, 1 dolphin was required to station at the surface on a bite plate, located $5.5 \mathrm{~m}$ directly in front of the sample screen. The bite plate was $46 \mathrm{~cm}$ long, $9 \mathrm{~cm}$ wide, and $2.5 \mathrm{~cm}$ thick and was constructed from PVC plastic sheet covered with neoprene rubber. Both dolphins used the same bite plate. When the dolphin grasped the bite plate, his melon was held above the water's surface, while his lower jaw remained in the water (Figure 3). Anatomical (see C. S. Johnson, 1986, for a review) and behavioral (Brill et al., 1988) data indicate that, in this position, the dolphin could not inspect submerged objects by using echolocation, but could still hear sounds emitted underwater. The trainer then placed the sample behind the screen and cued the dolphin to release the bite plate and place his head inside one of two stationing hoops. One hoop was attached to the bottom of the bite 


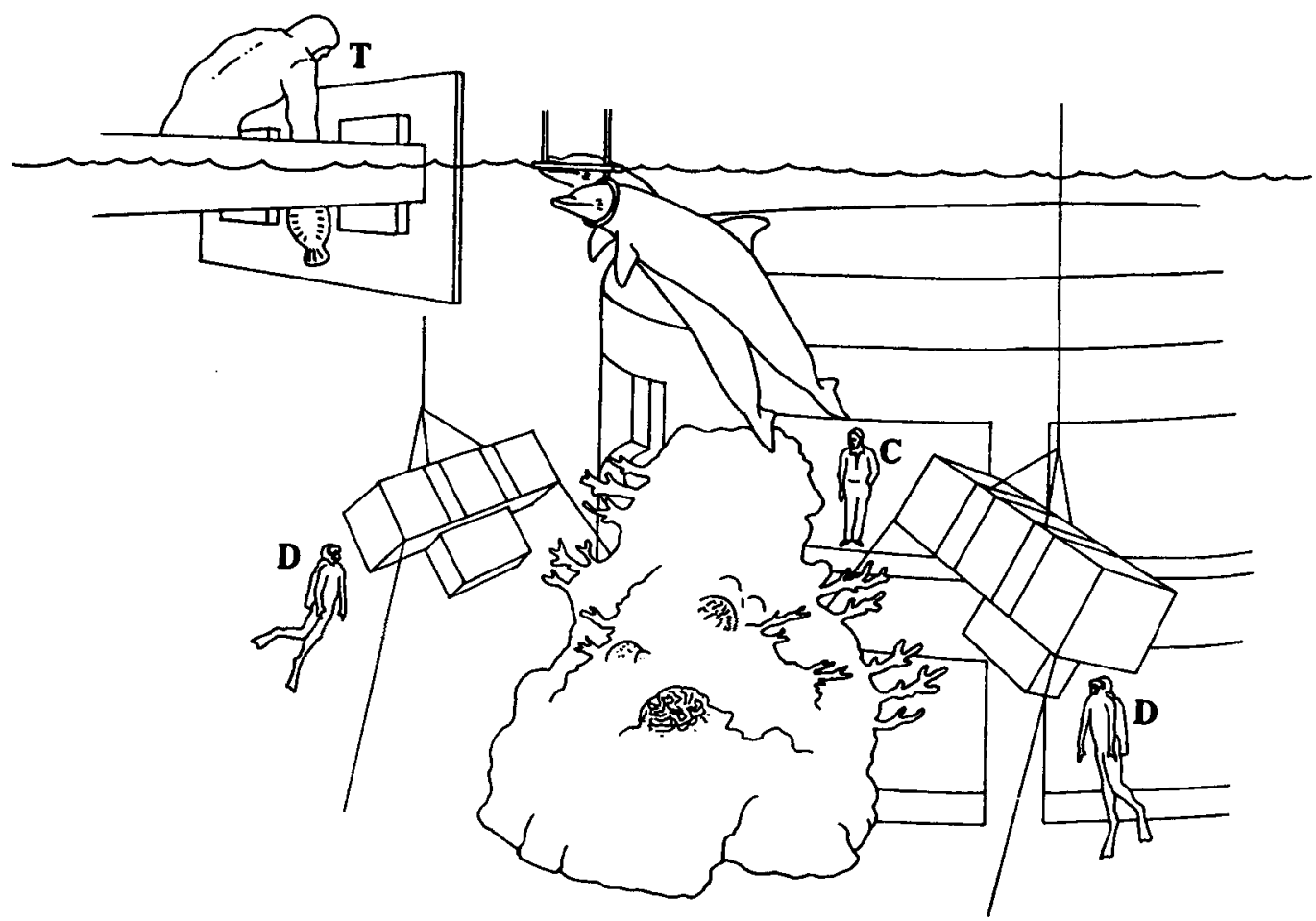

Figure 2. The positions of the experimenters, dolphins, and apparatus. The trainer $(T)$, working from a floating platform, held the sample object in position by hand behind a visual screen. The dolphins were positioned at the bite plate in front of the screen. Alternative objects were presented behind submerged visual screens located on either side of an artificial reef. One dolphin made selections from the screen on the left; the other made selections from the screen on the right. Scuba divers (D) on each side set up the objects for each trial and judged the dolphin's response. The session coordinator $(C)$, watching from an underwater window, recorded the dolphin's choice and announced whether it was correct or incorrect. From "Echolocation, Cognition, and the Dolphin's World," by H. E. Harley, M. J. Xitco, Jr., and H. L. Roitblat, 1995, in R. Kastelein, J. Thomas, and P. Nachtigall (Eds.), Sensory Systems of Aquatic Mammals (p. 537), Woerden, The Netherlands: De Spil. Copyright 1995 by De Spil. Reprinted with permission.

plate on each end. One dolphin used the hoop on the left; the other dolphin used the hoop on the right. The hoops were constructed of water-filled PVC plastic pipe and were $36 \mathrm{~cm}$ in diameter. They could be retracted up and out of the way during test trials. When each hoop was deployed, its center was located $30 \mathrm{~cm}$ below the surface. Once the dolphin was positioned inside the hoop, he inspected the sample by echolocating through the visually opaque screen. After approximately $10 \mathrm{sec}$, the trainer pulled the object out of the water. This cued the dolphin to dive to his choice station. The dolphin's task was to approach to within $30 \mathrm{~cm}$ of the object that matched the sample, and to point through the screen at the object with his rostrum for 2 sec. The dolphin's choice was judged by the diver at that choice station, who was ignorant of the identity of the sample. The session coordinator, watching from the underwater viewing area, recorded the dolphin's choice and announced to the diver and trainer whether it was correct or incorrect. Following a correct choice, the dolphin received an acoustic secondary reinforcer from the diver and returned to the trainer at the floating platform. The trainer then reinforced the dolphin with food and social interaction. Following an incorrect choice, the dolphin received only minimal social interaction from the trainer. The intertrial interval was approximately $90 \mathrm{sec}$. During this time, the diver exchanged the alternative objects from the previous trial with those for the next trial, and the 2nd dolphin ran a trial on the other side. The dolphins ran trials in alternation until they had completed up to 12 trials each. Sessions typically lasted $20-30 \mathrm{~min}$ and were run once or twice per day for up to 5 days per week.
Training. A learning set approach was used to train the matching-to-sample task. Each dolphin was initially presented with a set of three stimulus objects. After he achieved a criterion level of 20 correct responses across 25 consecutive trials, another set of three objects was presented. Each dolphin was presented with a total of six sets of objects. The sets are listed in Figure 1. The sets were presented to the dolphins in counterbalanced order. Individual sets were structured so that two of the objects had the same shape, two were made of the same material, and two of the objects were solid while one was hollow. This set structure was intended to teach the dolphins to make discriminations on the basis of all three object characteristics.

To simplify the matching task during acquisition, the dolphins were allowed to inspect the sample object from a distance of less than $1 \mathrm{~m}$, and only two alternative objects (the match and one distractor) were presented on each trial. In addition, the dolphins were not yet required to position themselves on the bite plate or in the stationing hoop during the presentation of the sample. After the dolphins achieved criterion performance with the sixth set of objects, a second distractor was added so that three alternatives were presented on each matching trial. The six sets of three objects were then merged to form one set of 18 stimuli, and the dolphins were run through approximately 1,260 training trials, during which each object was presented as the sample approximately 70 times. During this period, the bite plate and stationing hoop were introduced into the procedure, and the stationing apparatus was gradually backed away from the sample to its final position. 


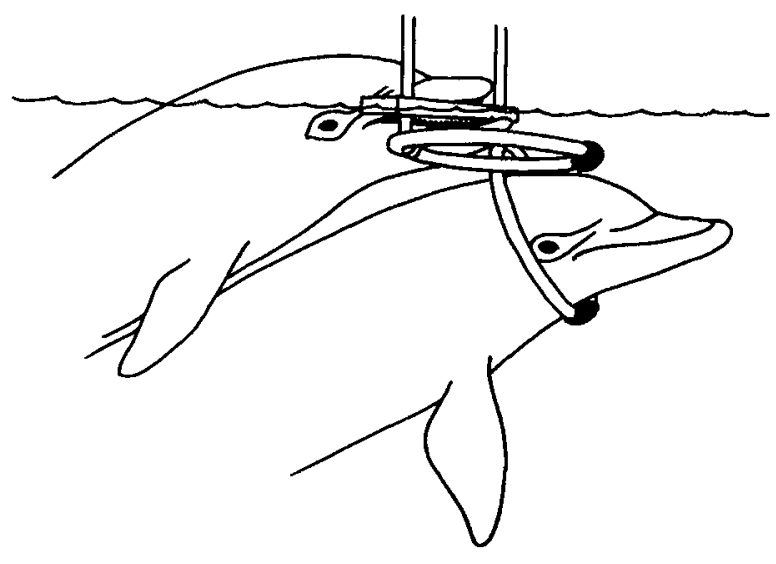

Figure 3. The dolphins at the bite plate. The dolphin in the foreground is shown in the listening position. When the dolphin grasped the bite plate, his melon was held above the surface. This prevented him from directing echolocation clicks at the sample object. The dolphin in the background is shown in the inspecting position. With his head in the hoop, the dolphin was free to examine the sample via echolocation.

In addition, 1 of the dolphins, Toby, was trained to dive, on an acoustic cue, to his set of alternative objects and make a choice immediately after releasing the bite plate, without first stationing in his hoop or inspecting a sample object. Training for Experiment 1 was conducted between November 9, 1988 and December $2,1991$.

Testing. "Test," or "passive," trials were introduced once the 2 dolphins demonstrated consistent performance with the shared set of 18 objects. On passive trials, both dolphins were sent simultaneously to the bite plate. To control for cues associated with the handling of the sample, the sample and a second sham object, which matched one of the two distractor objects, were placed behind the sample screen simultaneously. Before either dolphin was released from the bite plate, the sham object was slipped inside one of the acoustic boxes without removing it from the water. It remained in that box throughout the trial. The location of the sham object in the left or right box was assigned randomly. One of the dolphins, the inspector, was then cued to descend into his hoop to examine the sample object, which remained in "acoustic view." The other dolphin, the listener, was required to remain on the bite plate while the sample was presented (Figure 3). On passive trials, the same dolphin, Bob, was always the inspector, while the other dolphin, Toby, always acted as the listener. In this position, the distance between the dolphins, measured from the tips of their rostrums, was between 30 and $40 \mathrm{~cm}$. As such, they were within $5^{\circ}$ of each other, relative to the sample object. After 10-20 sec, the sample was slipped inside the other acoustic box, cuing the inspector to dive to his choice station. His departure, in turn, paired with the previously established cue, signaled the listener dolphin to dive to his separate choice station. The dolphins were reinforced for correct selections independently of the other dolphin's choice.

Each of the 18 stimuli was presented as the sample object three times, for a total of 54 unique passive trials. Only the final 36 passive trials included the sham presentation of an object that matched one of the two distractor objects. The identity of the object given the sham presentation was selected randomly from the two distractor objects assigned to that trial. Across three presentations, each sample object was paired against six different distractor objects. Distractors were assigned randomly, with the restriction that each object appear as a distractor six times, and that no objects of the same shape or material would be paired against each other. The positions of the alternative objects behind each dolphin's screen were assigned independently. On each trial, the position of the matching object behind the screen, in the left, right, or center position, was assigned randomly, with the restriction that it occurred in each of the three positions four times across any 12 consecutive trials. The positions of the distractor objects behind the screen were assigned randomly from the two positions not occupied by the matching object. During test sessions, up to 3 passive trials were run, intermixed with 9 active trials. Trials were run randomly with two restrictions: no session began with a passive trial, and no object appeared as an alternative object on 2 consecutive trials. Testing in Experiment 1 was completed in 27 sessions conducted between December 3 and 20, 1991.

\section{Results and Discussion}

Training. During each dolphin's initial training on the matching task, there was a significant decrease in the number of errors required in order to reach criterion across successive sets of stimuli [listener, 201, 51, 33, 5, $18,8, r(5)=-.78, p<.05$; inspector, $191,51,36,36$, $31,28, r(5)=-.73, p<.05]$. After acquisition, Toby was correct on 556 of $673(83 \%)$ active trials with the combined set of 18 stimuli in the three-alternative format; Bob was correct on 478 of $693(69 \%)$ active trials (chance was 33\%). Each dolphin's performance was significantly less accurate when the distance to the sample was increased in the next phase of training [Toby, $\chi^{2}(1)=$ $\left.15.6, p<.001 ; \mathrm{Bob}, \chi^{2}(1)=14.1, p<.001\right]$. During distance training, Toby was correct on 428 of $583(73 \%)$ active trials; Bob was correct on 344 of $578(60 \%)$ active trials. Overall, Toby's performance on each of the $18 \mathrm{ob}-$ jects was significantly better than chance (for each object, $p<.05$, summed binomial test; $M=77 \%$ correct, $S D=$ $10 \%$ ). Bob's performance was significantly better than chance for 15 of the 18 objects (for each object, $p<.05$, summed binomial test; $M=62 \%$ correct, $S D=17 \%$ ). When the solid ceramic cylinder, wood plate, and solid wood cube were used as the sample, Bob's performance was not significantly different from chance.

Testing. During testing, the listener, Toby, was able to select correctly the matching object on 27 of $54(50 \%)$ passive trials, significantly better than chance for a threealternative task $(p<.05$, summed binomial test). This suggests that the listener received information about the sample by eavesdropping on echoes generated by the inspector, Bob. The listener's performance when the inspector made a correct choice $(17$ of 30 , or $57 \% ; p<.01$, summed binomial test) was numerically higher than when the inspector made an error ( 10 of 24 , or $42 \%$; $>$ .05 , summed binomial test), but this difference was not significant $\left[\chi^{2}(1)=1.2, p>.05\right]$. When the inspector made an error, the listener was just as likely to choose either of the objects not chosen by the inspector. The listener was correct on 10 trials, made the same error as the inspector on 9 trials, and made a unique error on 5 trials. In addition, there was no relationship between the position of the alternative object selected by the listener and that of the object selected by the inspector $\left[\chi^{2}(4)=1.91\right.$, $p>.05]$. When the listener made an error, he was not more likely to choose the distractor object that matched 
the sham object. He chose the distractor that matched the sham object five times and chose the other distractor nine times. This suggests that cues associated with the handling of the sample did not contribute to the listener's successful responses.

The listener made at least one correct response to 15 of the 18 objects. He correctly selected one object, the ceramic plate, each time it was the match but never chose it when it was a distractor. The listener's performance was adversely affected by a significant bias to select wooden objects ( 33 of 54 trials, or $61 \% ; p<.0001$, summed binomial test). One wooden object was presented as an alternative object on each trial. During the test, the listener correctly selected a wooden object on 13 trials but selected one in error on 20 trials. If trials in which he chose a wooden object are excluded, his performance improved to 14 correct responses on 21 passive trials $(67 \% ; p<.01$, summed binomial test). On these trials, the listener's performance was again not contingent on the inspector's performance $\left[\chi^{2}(2)=.095\right.$, $p>.05]$. When the inspector made a correct choice (11 trials), the listener chose the match on 7 trials and a distractor on 4 trials. When the inspector made an error (10 trials), the listener chose the match on 7 trials, selected the other distractor on 3 trials, and never chose the same distractor as did the inspector. At no point in his training or testing did the dolphin that acted as the listener demonstrate a bias toward wooden objects when he was allowed to inspect the sample on active trials. However, the dolphin that acted as the inspector, Bob, had exhibited a bias to select wooden objects from time to time during training. This bias reemerged during the test. The inspector had a significant bias to select wooden objects on both passive ( 28 of 54 trials, or $52 \% ; p<.01$, summed binomial test) and active trials (54 of 94 trials, or 57\%; $p<$ .001 , summed binomial test).

The inspector was correct on 30 of $54(56 \%)$ passive trials. As such, his performance was not significantly better than that of the listener, who did not inspect the sample $\left[\chi^{2}(1)=.334, p>.05\right]$. Bob was also correct on 65 of $94(69 \%)$ active trials during the test. Therefore, although his performance on passive trials was lower, it was not significantly different from that on active trials $\left[\chi^{2}(1)=2.97, p>.05\right]$. On active trials, when he was allowed to inspect the sample, Toby was correct on 90 of $99(91 \%)$ trials during the test, which was significantly better than his performance as the listener on passive trials $\left[\chi^{2}(1)=32.5, p<.01\right]$.

\section{EXPERIMENT 2}

During training in Experiment 1, the dolphins may have developed superstitious responses in the presence of particular stimuli. Since both dolphins had experience with the same objects, the listener could have used the production of such arbitrary cues by the inspector to identify the sample on passive trials (Bastian, 1967; Bastian, Wall, \& Anderson, 1968; Zanin, Markov, \& Sidor- ova, 1990). To control for this possibility a second experiment was conducted with objects familiar to only 1 of the dolphins on passive trials.

\section{Method}

Subjects and Apparatus. The subjects and apparatus were the same as those used in Experiment 1. Nine of the stimuli from Experiment $l$ were used. They were the aluminum grill, solid aluminum cube, solid aluminum cylinder, ceramic grill, ceramic plate, solid ceramic cylinder, wood plate, solid wood cube, and solid wood cylinder. In addition, 18 new stimuli were used. These objects are described in Figure 4. Each of the new objects was unique in size and shape, and they were made from a wider variety of materials

Three hydrophones were added to the apparatus to detect the dolphins' echolocation signals at the bite plate during passive trials. Sounds produced by the inspector were received by one hydrophone (USRD, Model F42D) positioned midway between the bite plate and the sample object at a depth of $30 \mathrm{~cm}$. A second, identical hydrophone was placed inside a flexible, water-filled headrest constructed from a vinyl shower cap. The headrest was mounted $8 \mathrm{~cm}$ above the bite plate. When the listener grasped the bite plate during passive trials, he pressed his melon into the headrest, acoustically coupling it to the hydrophone. The outputs from these hydrophones were amplified by separate preamplifiers (Princeton Applied Research, Model 113) and subsequently passed through a two-channel oscilloscope (Tektronix, Model 2211). A third, low-frequency, hydrophone (custom built), capable of responding to frequencies up to approximately $30 \mathrm{kHz}$, was attached to the front of the bite plate. It was situated between the two stationing hoops, at a depth of $15 \mathrm{~cm}$. The output from this hydrophone was patched into the external microphone jack of a video camera (Sony, Model CCD-V801). On passive trials, the video camera recorded the output of the oscilloscope screen and the audio output of the low-frequency hydrophone. This provided a record of the gross production of echolocation signals by both dolphins at the bite plate during passive trials. However, the videotape record was not adequate to document the number of echolocation signals produced or the amplitude or frequency structure of individual clicks.

Training. Each dolphin was trained to perform the matching task with his own unique set of nine stimuli. The set for each dolphin is shown in Figure 4. The stimuli are listed in the order in which they were introduced to the dolphins. As in the training for Experiment 1, the dolphins were allowed to inspect the sample from a distance of $1 \mathrm{~m}$ and only two alternative objects (the match and one distractor) were presented on each trial. Initially, each dolphin worked with only the first four objects in his set. A fifth object was added to the set after the dolphin achieved a criterion of $80 \%$ correct responses across consecutive trials in which each object was paired as the sample against each of the other objects in the set. Additional objects were added to each dolphin's set in this manner until all nine objects had been introduced. After the dolphin achieved criterion performance with all nine objects, a second distractor was reintroduced so that again three alternatives were presented on each matching trial. The stationing apparatus was then gradually returned to its position $5.5 \mathrm{~m}$ in front of the sample screen. Overall, each dolphin was trained for approximately 855 trials with his own objects. Of these trials, 532 trials were run with three alternatives and all nine objects for Toby, whereas 428 trials were run for Bob. During this portion of the training, each object was presented as the sample approximately an equal number of times. In addition, 181 passive trials with the objects from Experiment 1 were run, intermixed with the training trials, to maintain the dolphin's performance in the testing format. Training for Experiment 2 was conducted between January 26 , 1992 and April 9, 1993. 
Listener's Objects

\begin{tabular}{|c|c|}
\hline $\begin{array}{l}\text { Brass Flower Tub } \\
27.5 \times 10 \times 8 ; 0.4\end{array}$ & $\begin{array}{l}\text { Glass Fish } \\
21 \times 25.7 \times 0.4\end{array}$ \\
\hline $\begin{array}{l}\text { Glass Strawberry } \\
14 \times 11.5 \times 3.5 ; 0.5\end{array}$ & $\begin{array}{l}\text { Steel Shelving Bracket } \\
29.5 \times 24 \times 2 ; 0.4\end{array}$ \\
\hline $\begin{array}{l}\text { Steel "Tongue" Bracket } \\
17 \times 6.2 \times 3 ; 0.4\end{array}$ & $\begin{array}{l}\text { Steel-Wood Barbecue Poker } \\
16 \times 2.6 \times 2.6\end{array}$ \\
\hline $\begin{array}{l}\text { Steel Fish } \\
13.5 \times 29 \times 0.4\end{array}$ & $\begin{array}{l}\text { Styrofoam Cone } \\
23 \times 9.5 \times 9.5\end{array}$ \\
\hline $\begin{array}{l}\text { Fiberboard Mitt } \\
30 \times 26.5 \times 1.3\end{array}$ & $\begin{array}{l}\text { Red Clay Pot with Steel Bolt } \\
17 \times 17 \times 4 ; 1\end{array}$ \\
\hline $\begin{array}{l}\text { Plastic Double Cross } \\
24 \times 27 \times 27 ; 0.3\end{array}$ & $\begin{array}{l}\text { Wood "M" } \\
16.5 \times 14 \times 1.7\end{array}$ \\
\hline $\begin{array}{l}\text { Ceramic Mug } \\
13 \times 10 \times 10 ; 0.6\end{array}$ & $\begin{array}{l}\text { Wood Snack Bowl } \\
30 \times 30 \times 4.2 ; 0.2\end{array}$ \\
\hline $\begin{array}{l}\text { Wood Spoons } \\
34.1 \times 28.2 \times 1\end{array}$ & $\begin{array}{l}\text { Plastic Pipe } \\
15.5 \times 11.5 \times 11.5 ; 0.9\end{array}$ \\
\hline $\begin{array}{l}\text { Styrofoam Balls } \\
22 \times 5.5 \times 5.5\end{array}$ & $\begin{array}{l}\text { Steel Peanut Dish } \\
17 \times 18 \times 18 ; 0.5\end{array}$ \\
\hline
\end{tabular}

Inspector's Objects

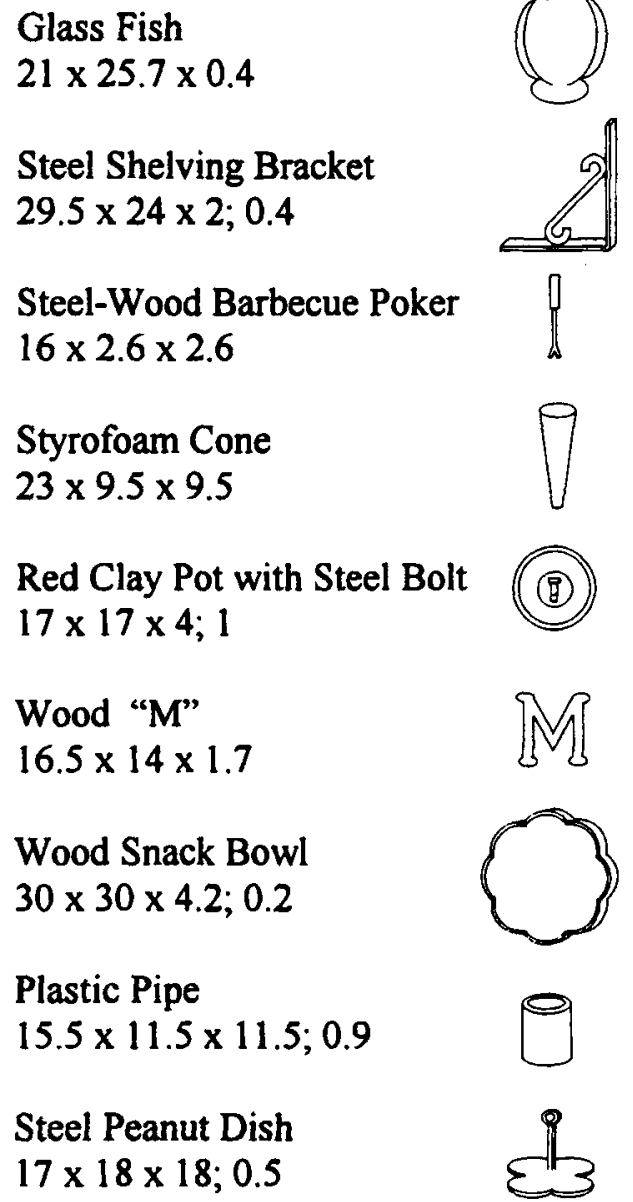


of 406 (79\%) active trials, whereas Bob was correct on 237 of $401(59 \%)$ active trials. Overall, Toby's performance on eight of his nine objects was significantly better than chance (for each object $p<.05$, summed binomial test; $M=82 \%$ correct, $S D=17 \%$ ). Toby's performance when the steel "tongue" bracket was the sample was not significantly different from chance. Bob's performance was significantly better than chance for seven of his nine objects ( $p<.05$, summed binomial test; $M=62 \%$ correct, $S D=16 \%$ ). When the plastic pipe and steel-wood poker were used as the sample, Bob's performance was not significantly different from chance. During training Toby, acting as the listener, was correct on 102 of 181 $(56 \% ; p<.001$, summed binomial test) passive trials with the shared objects from Experiment 1, whereas Bob, acting as the inspector, was correct on 108 of the $181(60 \%$; $p<.001$, summed binomial test) passive trials. As such, neither dolphin's performance was significantly different from that on passive trials during testing in Experiment 1 [listener, $\chi^{2}(1)=.678, p>.05$; inspector, $\chi^{2}(1)=$ $.290, p>.05]$.

Testing. The listener's performance during testing is summarized in Table 1. During testing, the listener was able to select the matching object on a significant number of passive trials ( 51 of 108 , or $47 \% ; p<.01$, summed binomial test). However, when trials with the shared objects were excluded, the listener's performance was not significantly better than chance $(31$ of 72 , or $43 \%$; $>$ .05 , summed binomial test). Although this result raises the possibility that arbitrary cues associated with the shared objects guided the listener's correct responses, further inspection of the data supports an alternative explanation. The listener did select the matching object, both for objects familiar only to himself and objects familiar only to the inspector, but only when the inspector went on to make a correct choice. When the inspector made a correct choice, the listener was correct on 20 of 34 trials $(59 \% ; p<.01$, summed binomial test). On the other hand, when the inspector made an incorrect response, the listener was correct on only 11 of 38 trials $(29 \% ; p>.05$, summed binomial test). Although dolphins have frequently been found to generalize their matching performance to novel objects (see, e.g., Herman et al., 1989), the number and signal strength of clicks that they emit do vary across trials (e.g., Roitblat et al., 1990a). The inspector dolphin may have emitted too few clicks or clicks that were too weak on the trials on which he made an error, thereby preventing the listener from obtaining necessary information about the identity of the sample.

Alternative explanations for the dependency between the correct performance of the listener and the correct response of the inspector can be discounted. On the passive trials in which the inspector made an error, the listener was just as likely to choose either of the objects not chosen by the inspector. On passive trials with objects familiar to only 1 dolphin, when the inspector made an error the listener was correct on 11 trials, made the same error as the inspector on 14 trials, and made a unique error on 13 trials. In addition, there was no relationship between the position of the alternative object selected by the listener and that of the object selected by the inspector $\left[\chi^{2}(4)=5.10, p>.05\right]$. When the listener made an error, he was not more likely to choose the distractor object which matched the sham object. He chose the distractor which matched the sham object 19 times and chose the other distractor 22 times. This suggests again that cues associated with the handling of the sample did not contribute to the listener's successful responses.

The listener's performance on passive trials was not significantly lower than that of the inspector, who was allowed to examine the sample [overall, $\chi^{2}(1)=.907$, $p>.05$; shared objects, $\chi^{2}(1)=.935, p>.05$; inspector's objects, $\chi^{2}(1)=.892, p>.05$; listener's objects, $\left.\chi^{2}(1)=.059, p>.05\right]$. The listener's lower performance on passive trials, compared with that in Experiment 1, may have been attributable largely to the inspector's lower performance with objects unfamiliar to him. The inspector was correct on only 13 of $36(33 \%)$ passive trials with the listener's objects. The inspector's performance was significantly better on passive trials with objects familiar to him. He was correct on 45 of $72(63 \%)$ passive trials with either his own objects or the shared objects $\left[\chi^{2}(1)=6.72, p<.01\right]$.

The listener made at least one correct response to seven of the nine shared objects, to seven of his nine unique objects, and to all nine of the inspector's objects. The listener's performance on passive trials with the shared objects was again adversely affected by a significant bias to select wooden objects ( 28 of 36 trials, or $78 \% ; p<.001$, summed binomial test). The listener correctly selected a wooden object on 12 trials, but selected

Table 1

The Listener's Performance on Passive Trials During Experiment 2

\begin{tabular}{lrcc}
\hline & & \multicolumn{2}{c}{ Objects Familiar to Only One Dolphin } \\
\cline { 4 - 4 } & Shared Objects & Listener's Objects & Inspector's Objects \\
\hline Inspector correct & $15 / 24=63 \% *$ & $8 / 13=62 \% \dagger$ & $12 / 21=57 \% \dagger$ \\
Inspector incorrect & $5 / 12=42 \% \ddagger$ & $6 / 23=26 \% \ddagger$ & $5 / 15=33 \% \ddagger$ \\
\hline
\end{tabular}

Note- - The number of correct responses is presented as a function of the inspector's response and the object type. All tests summed binomial test. ${ }^{*} p<.01 .{ }^{\dagger} p<.05$. ${ }^{t} p>$.05. From "Echolocation, Cognition, and the Dolphin's World," by H. E. Harley, M. J. Xitco, Jr., and H. L. Roitblat, 1995, in R. Kastelein, J. Thomas, and P. Nachtigall (Eds.), Sensory Systems of Aquatic Mammals (p. 539), Woerden, The Netherlands: De Spil. Copyright 1995 by De Spil, Reprinted with permission. 
one in error on 16 trials, accounting for all of his errors with shared objects during the test. If trials in which he chose a wooden object were excluded, his performance with the shared objects improved to eight correct responses on 8 passive trials $(p<.001$, summed binomial test).

No obvious biases were present in the listener's performance with his own objects on passive trials. However, with the inspector's objects, the listener did exhibit a significant bias to select one object, the styrofoam cone ( 11 of 12 trials, or $92 \% ; p<.001$, summed binomial test). The listener chose the styrofoam cone on all 4 trials when it was the match, and on 7 of the 8 trials for which it was a distractor. If trials in which he chose the styrofoam cone were excluded, his performance with the inspector's objects improved to 13 correct responses on 25 passive trials $(52 \% ; p<.05$, summed binomial test). On these trials, the listener's performance was not contingent on the inspector's performance $\left[\chi^{2}(1)=.987, p>\right.$ $.05]$. When the inspector made a correct choice (13 trials), the listener chose the match on 8 trials and a distractor on 5 trials. When the inspector made an error (12 trials), the listener chose the match on 5 trials, chose the same distractor as did the inspector on 5 trials, and selected the other distractor on 2 trials. At no point in his training or testing did the dolphin who acted as the listener, Toby, demonstrate a bias toward his styrofoam object, styrofoam balls. During the test, Toby performed perfectly with styrofoam balls on active trials when he was allowed to inspect the sample. He correctly selected it on each of the 12 trials for which it was the match, and never selected it on the 24 trials for which it was a distractor. In addition, on the 12 passive trials that included styrofoam balls as an alternative object, Toby, acting as the listener, selected it only four times, once when it was the match, and three times when it was a distractor. In contrast, the dolphin who acted as the inspector, Bob, exhibited a significant bias to select styrofoam objects during the test. On active and passive trials, he selected his styrofoam object, the styrofoam cone, on 13 of 16 trials when it was the match, but also selected it on 11 of 32 trials when it was a distractor (in all, 24 of 48 trials, or $50 \% ; p<.05$, summed binomial test). The inspector chose the unfamiliar styrofoam object, styrofoam balls, on 10 of the 12 passive trials that included it as an alternative $(83 \% ; p<.001$, summed binomial test). He selected it twice when it was the match, but chose it on all 8 of the trials for which it was a distractor. The inspector's bias to select the unfamiliar styrofoam object was significantly stronger than his bias to choose his familiar styrofoam object $\left[\chi^{2}(1)=4.34, p<.05\right]$.

The inspector was correct on 24 of $36(66 \%)$ passive trials and 83 of $108(77 \%)$ active trials with the shared objects, and on 21 of $36(58 \%)$ passive trials and 65 of $108(60 \%)$ active trials with his own objects. As such, his performance on passive trials was not significantly different from that on active trials [shared objects, $\chi^{2}(1)=1.47, p>.05$; inspector's objects, $\chi^{2}(1)=.038$, $p>.05]$. Toby was correct on 101 of $108(94 \%)$ active trials with the shared objects, and on 93 of $108(86 \%)$ active trials with his own objects. Therefore, his performance on active trials, when he inspected the sample, was significantly better than his performance as the listener on passive trials with the corresponding objects [shared objects, $\chi^{2}(1)=29.0, p<.01$; listener's objects, $\left.\chi^{2}(1)=31.5, p<.01\right]$.

Echolocation clicks were detected from the listener while he grasped the bite plate on only 5 of 108 passive trials, and he was correct on only 2 of those trials. Clearly, his responses were not aided by any covert echoic inspection of the sample while he was stationed on the bite plate. Echolocation clicks were detected from the inspector while he examined the sample on all passive trials. However, only a small sample of clicks were captured on the video record. The number and amplitude of these clicks were highly variable. Both dolphins also produced a number of whistle vocalizations on test trials. A log linear analysis was performed to determine whether the production of whistles was related to the dolphins' performance. However, the best fitting model $\left[\chi^{2}(3)=1.73\right.$, $p=.63$ ) indicated that there was no significant difference in performance when the dolphins whistled as opposed to when they did not.

\section{GENERAL DISCUSSION}

The results suggest that one dolphin can garner significant information about an object in the environment by listening to the sensory efforts of a companion. This suggests the possibility that echolocation may play a wider role in the dolphin's interactions, and it provides preliminary support for the "eavesdropping" hypotheses offered by Jerison (1986) and Dawson (1991). As dolphins employ their sonar, information about objects in the environment is generated. This information is accessible to both the inspecting dolphin and, potentially, other dolphins. The transmission of this information to others is simply a by-product of the dolphin's active sensory system. The behavioral measures of the present study were not intended to determine whether this information resided in characteristic changes in the outgoing clicks produced by the inspector as he examined particular sample objects or in the resultant echoes themselves. However, in light of the available data (Au, 1993), it seems reasonable to conclude that the listener's performance was guided by object-specific or feature-specific information that he received by listening to echoes generated as the inspector examined the sample. As such, the results suggest that, unlike the case for bats (Suga, 1990), echolocation signal production is not necessarily an integral part of processing some features of echoes for dolphins.

In many ways, the listener's degraded performance on passive trials closely resembled the typical performance of the inspector. The listener's performance was not significantly worse than the inspector's on passive trials, even though the inspector examined the sample while the listener did not. When acting as the listener, the dolphin 
also spontaneously developed response biases that matched those exhibited by the inspector throughout the study. The dolphin never exhibited these biases when he was allowed to inspect the sample himself on active trials. One possible explanation for the similar performance of the two dolphins is that both dolphins were experiencing comparable difficulties in detecting and discriminating echoes. For the inspector, lower choice accuracy and strong biases developed during training when the distance to the sample object was increased. Perhaps forcing the other dolphin to operate as a listener affected his ability to detect and discriminate echoes in a manner similar to the effect of increasing target distance.

The pattern of the listener's correct and incorrect responses on passive trials, and his bias to select particular objects or groups of objects over others, may provide some insight into the nature of the information that he used in order to make a choice. Information related to material seems to have played an important role. The listener demonstrated a strong bias to select wooden objects when working with the shared objects in both experiments. Wooden objects would be expected to yield highly attenuated echoes relative to the aluminum and ceramic objects that they were paired against $(\mathrm{Au}$, personal communication, December 1989). The listener may have chosen wooden objects when he did not detect a strong echo during the inspector's examination of the sample. The listener's perfect performance with the ceramic plate in Experiment 1, and the fact that he made only correct responses to aluminum and ceramic shared objects in Experiment 2, indicate that the listener could identify these objects and make discriminations between them. This suggests that cues such as within-echo highlights were available to the listener, but perhaps only when he received relatively loud echoes. The implication of the listener's bias toward the unfamiliar styrofoam object is less clear. The inspector also had a bias to select styrofoam objects, especially the one that was unfamiliar to him. Helweg et al. (1996) used styrofoam objects as echolocation stimuli in part because they are highly reflective and yield strong echoes. These strong echoes may have made the unfamiliar styrofoam objects attractive to the dolphins as they approached the alternatives to make a choice.

The capacity to ascertain object attributes by listening in on the echoes of others may affect dolphin social behavior. For example, some swimming formations might be more favorable for passive listening than others. In the present study, the dolphins were required to remain very close to one another, oriented in the same direction. This position was adopted because dolphin echolocation clicks (Au, Moore, \& Pawloski, 1986) and dolphin hearing (Au \& Moore, 1984) are both highly directional, limited to a cone of about $10^{\circ}$. It is interesting to note that, although he was not required to, the listener often slid along the bite plate to position himself even closer to the inspector after the other dolphin descended to his stationing hoop. Helweg et al. (1996) demonstrated that the echo returned by an object often depends strongly on the angle from which it is ensonified. Two dolphins would have to be closely aligned before one dolphin would receive information from an ensonified object that was comparable to that received by the dolphin transmitting the echolocation clicks. Therefore, the animals may need to remain in close proximity in order to listen to each other's echoes effectively. Dolphins are routinely seen swimming in such close association, both in the wild and in captivity. However, a listening dolphin might not need information comparable to that received by an actively echolocating animal to glean some object features. Other positions relative to the inspector and the target being examined, especially those some distance removed from the surface and its associated reflection, might allow a listening dolphin to receive information characterizing some features of objects. In Scronce and C. S. Johnson's (1976) detection study, the target object was ensonified at close range by an artificial projector oriented at an angle of at least $45^{\circ}$ relative to the listening dolphin, who was stationed as far as $80 \mathrm{~m}$ away. Information beyond that required to perform the detection task may have been available to the listening dolphin. A systematic examination to determine effective listening positions might show how eavesdropping constrains, or perhaps expands, the structure of dolphin groups.

There may be other energetic, perceptual, or social advantages to listening over actively echolocating. Preliminary evidence of measurable metabolic costs associated with echolocation (Cole \& Speakman, 1993) is one example that offers a significant incentive for listening to echoes generated by the echoic inspections of companions. The role that such a capacity might play in the sensory, communicative, and even social scheme of dolphin life could be far reaching and seems worthy of future study.

\section{REFERENCES}

Au, W. W. L. (1993). The sonar of dolphins. New York: SpringerVerlag.

Au, W. W. L., Carder, D. A., Penner, R. H., \& Scronce, B. L. (1985). Demonstration of adaptation in beluga whale echolocation signals. Journal of the Acoustical Society of America, 77, 726-730.

Au, W. W. L., \& Hammer, C. E. (1980). Target recognition via echolocation by the bottlenose dolphin, Tursiops truncatus. In R.-G. Busnel \& J. F. Fish (Eds.), Animal sonar systems (pp. 855-858). New York: Plenum.

Au, W. W. L., \& Moore, P. W. B. (1984). Receiving beam patterns and directivity indices of the Atlantic bottlenose dolphin (Tursiops truncatus). Journal of the Acoustical Society of America, 75, 255-262.

Au, W. W. L., Moore, P. W. B., \& Martin, S. W. (1987). Phantom electronic target for dolphin sonar research. Journal of the Acoustical Society of America, 82, 711-713.

Au, W. W. L., Moore, P. W. B., \& Pawloski, D. (1986). Echolocation transmitting beam of the Atlantic bottlenose dolphin. Journal of the Acoustical Society of America, 80, 688-691

Au, W. W. L., Schusterman, R. J., \& Kersting, D. A. (1980). Spherecylinder discrimination via echolocation of Tursiops truncatus. In R.-G. Busnel \& J. F. Fish (Eds.), Animal sonar systems (pp. 859862). New York: Plenum.

Bagdonis, A., Bel.'kovich, V. M., \& Krushinskaya, N. L. (1970). Interaction of analyzers in dolphins during discrimination of geometrical figures. Journal of Higher Neural Activity, 20, 1070-1075. 
[Also available in K. J. Diercks (Ed.) (1974). A collection of foreign language papers on the subjects of biological sonar systems (Tech. Rep. No. 74-9) Austin: University of Texas, Applied Research Laboratory.]

BARCLAY, R. M. R. (1982). Interindividual use of echolocation calls: Eavesdropping by bats. Behavioral Ecology \& Sociobiology, 10 271.275 .

BASTIAN, J. (1967). The transmission of arbitrary environmental information between bottlenose dolphins. In R.-G. Busnel (Ed.), Animal sonar systems: Biology and bionics (Vol. 2, pp. 803-873). Jouy-en-Josas, France: Laboratoire de Physiologie Acoustique.

Bastian, J., WALL, C., \& ANDERson, C. L. (1968). Further investigation of the transmission of arbitrary environmental information between bottlenose dolphins (Tech. Paper 109, pp. 1-40). San Diego, CA: Naval Undersea Warfare Center.

Bel'kovich, V. M., \& Dubrovskiy, N. A. (1976). Sensory bases of cetacean orientation. Leningrad: Nauka.

Brill, R. L., Sevenich, M. L., Sullivan, T, J., Sustman, J. D., \& WiTT, R. E. (1988). Behavioral evidence for hearing through the lower jaw by an echolocating dolphin (Tursiops truncatus). Marine Mammal Science, 4, 223-230.

Caldwell, D. K., \& Caldwell, M. C. (1977). Cetaceans. In T. A. Sebeok (Ed.), How animals communicate (pp. 794-808). Bloomington: Indiana University Press.

Cole, K. R., \& Speakman, J. R. (1993, November). Do cetaceans have elevated resting metabolic rates? Paper presented at the Tenth Biennial Conference on the Biology of Marine Mammals, Galveston, TX

Dawson, S. M. (1991). Clicks and communication: The behavioral and social contexts of Hector's dolphin vocalizations. Ethology, $\mathbf{8 8}$ 265-276.

Evans, W. E., \& Powell, B. A. (1967). Discrimination of different metallic plates by an echolocating delphinid. In R.-G. Busnel (Ed.), Animal sonar systems: Biology and bionics (Vol. 1, pp. 363-382). Jouy-en-Josas, France: Laboratoire de Physiologie Acoustique.

FENTON, M. B. (1980). Adaptiveness and ecology of echolocation in terrestrial (aerial) systems. In R.-G. Busnel \& J. F. Fish, (Eds.), Animal sonar systems (pp. 427-446). New York: Plenum.

Hammer, C. E., \& AU, W. W. L. (1980). Porpoise echo-recognition: An analysis of controlling target characteristics. Journal of the Acoustical Society of America, 68, 1285-1293.

Harley, H. E., Xitco, M. J., JR., \& Roitblat, H. L. (1995). Echolocation, cognition, and the dolphin's world. In R. Kastelein, J. Thomas, \& P. Nachtigall (Eds.), Sensory systems of aquatic mammals (pp. 515-528). Woerden, The Netherlands: De Spil.

Helweg, D. A., Roitblat, H. L., Nachtigall, P. E., \& Hautus, M. J (1996). Recognition of aspect-dependent three-dimensional objects by an echolocating Atlantic bottlenose dolphin. Journal of Experimental Psychology: Animal Behavior Processes, 22, 19-31.

Herman, L. M., \& Gordon, J. A. (1974). Auditory delayed matching in the bottlenosed dolphin. Journal of the Experimental Analysis of Behavior, 21, 19-26.

Herman, L. M., Hovancik, J. R., Gory, J. D., \& Bradshaw, G. L. (1989). Generalization of visual matching by a bottlenosed dolphin (Tursiops truncatus): Evidence for invariance of cognitive performance with visual and auditory materials. Journal of Experimental Psychology: Animal Behavior Processes, 15, 124-136.

Herman, L. M., \& Tavolga, W. N. (1980). The communication systems of cetaceans. In L. M. Herman (Ed.), Cetacean behavior: Mechanisms and functions (pp. 149-209). New York: Wiley-Interscience

HUNTER, G. A. (1988). Visual delayed matching of two-dimensional forms by a bottlenose dolphin. Unpublished master's thesis, University of Hawaii.

JERISON, H. J. (1986). The perceptual worlds of dolphins. In R. J Schusterman, J. A. Thomas, \& F. G. Wood (Eds.), Dolphin cognition and behavior: A comparative approach (pp. 141-166). Hillsdale, NJ: Erlbaum.

JoHnson, C. M., \& Norris, K. S. (1986). Delphinid social organization and social behavior. In R. J. Schusterman, J. A. Thomas, \& F. G. Wood (Eds.), Dolphin cognition and behavior: A comparative approach (pp. 335-346). Hillsdale, NJ: Erlbaum.
Johnson, C. S. (1986). Dolphin audition and echolocation capacities. In R. J. Schusterman, J. A. Thomas, \& F. G. Wood (Eds.), Dolphin cognition and behavior: A comparative approach (pp. 115-136). Hillsdale, NJ: Eribaum.

JoHnson, R. A. (1980). Energy spectrum analysis in echolocation. In R.-G. Busnel \& J. F. Fish (Eds.), Animal sonar systems (pp. 673693). New York: Plenum.

LEONARD, M. L., \& FENTON, M. B. (1984). Echolocation calls of Euderma macultum (Vespertilionidae): Use in orientation and communication. Journal of Mammalogy, 65, 122-126.

MOORE, P. W. B. (1988). Dolphin echolocation and audition. In P. E. Nachtigall \& P. W. B. Moore (Eds.), Animal sonar: Processes and performance (pp. 161-168). New York: Plenum.

Moore, P. W. B., Hall, R. W., Friedl, W. A., \& Nachtigall, P. E (1984). The critical interval in dolphin echolocation: What is it? Journal of the Acoustical Society of America, 76, 314-317.

MOORE, P. W. B., \& PAWLOSKI, D. A. (1990). Investigations on the control of echolocation pulses in the dolphin. In J. A. Thomas \& R. Kastelein (Eds.), Dolphin sensory processes (pp. 305-316). New York: Plenum.

Morgane, P. J., Jacobs, M. S., \& Galaburda, A. (1986). Evolutionary morphology of the dolphin brain. In R. J. Schusterman, J. A. Thomas, \& F. G. Wood (Eds.), Dolphin cognition and behavior: $A$ comparative approach (pp. 5-29). Hillsdale, NJ: Erlbaum.

Nachtigall, P. E. (1980). Odontocete echolocation performance on object size, shape and material. In R.-G. Busnel \& J. F. Fish (Eds.), Animal sonar systems (pp. 71-96). New York: Plenum

Nachtigall, P. E., Murchison, A. E., \& Au, W. W. L. (1980). Cylinder and cube shape discrimination by an echolocating blindfolded bottlenosed dolphin. In R.-G. Busnel \& J. F. Fish (Eds.), Animal sonar systems (pp. 945-947). New York: Plenum

PENNER, R. H. (1988). Attention and detection in dolphin echolocation. In P. E. Nachtigall \& P. W. B. Moore (Eds.), Animal sonar: Process and performance (pp. 707-713). New York: Plenum.

Roitblat, H. L., Moore, P. W. B., Nachtigall, P. E., \& Penner, R. H (1991). Natural dolphin echo recognition using an integrator gateway network. In D. S. Touretsky, J. E. Moody, \& R. Lippman (Eds.), Advances in neural information processing systems 3 (pp. 273281). San Mateo, CA: Morgan Kaufmann.

Roitblat, H. L., Penner, R. H., \& Nachtigall, P. E. (1990a). Attention and decision-making in echolocation matching-to-sample by a bottlenose dolphin (Tursiops truncatus): The microstructure of decision-making. In J. Thomas \& R. Kastelein (Eds.), Sensory abilities of cetaceans (pp. 665-676). New York: Plenum.

Roitblat, H. L., Penner, R. H., \& Nachtigall, P. E. (1990b). Matching-to-sample by an echolocating dolphin. Journal of Experimental Psychology: Animal Behavior Processes, 16, 85-95.

Romanenko, E. V. (1990). Purposeful changes in the structure of echolocation pulses in Tursiops truncatus. In J. Thomas \& R. Kastelein (Eds.), Sensory abilities of cetaceans (pp. 317-319). New York: Plenum.

SCronce, B. L., \& Johnson, C. S. (1976). Bistatic target detection by a bottlenosed porpoise. Journal of the Acoustical Society of America, 59, 1001-1002.

SugA, N. (1990). Cortical computational maps for auditory imaging. Neural Networks, 3, 3-21

THOMPSON, R. K. R., \& HERMAN, L. M. (1975). Underwater frequency discrimination in the bottlenosed dolphin $(1-140 \mathrm{kHz})$ and the human $(1-8 \mathrm{kHz})$. Journal of the Acoustical Society of America, 57 , 943-948.

Zanin, A. V., Markov, V. I., \& Sidorova, I. E. (1990). The ability of bottlenose dolphins, Tursiops truncatus, to report arbitrary information. In J. Thomas \& R. Kastelein (Eds.), Sensory abilities of cetaceans (pp. 685-697). New York: Plenum.

(Manuscript received July 18, 1995; revision accepted for publication October $13,1995$. 